\title{
Els epistolaris i la història cultural
}

\author{
Albert Ghanime \\ aghanime@ub.edu \\ Universitat de Barcelona \\ Facultat d'Història \\ Departament d'Història i Arqueologia \\ Carrer de Montalegre, 6 \\ 08001 Barcelona
}

Valentí Valenciano, El treball ciclopi de dos historiadors. L'Epistolari de Lluis de Vilafranca a Joan Ramis i Ramis (I8I7-I8r9), Mallorca: Ajuntament de Vilafranca de Bonany, 2020.

El menorquí Valentí Valenciano, llicenciat en Ciències Físiques per la Universitat de Barcelona i doctor en Història per la Universitat de les Illes Balears, historiador de llarg recorregut, especialitzat en la història mallorquina i balear de la primera meitat del segle XIX, dedicat molt especialment a estudiar el liberalisme illenc, ens presenta un rigorós exercici de reconstrucció microhistòrica a partir de les cartes que el frare Lluís de Vilafranca va enviar a l'erudit i historiador Joan Ramis i Ramis entre I8I7 i I819.

Lobra consta de vuit apartats repartits en 208 pàgines, però podem distingir dues parts clarament diferenciades: el primer bloc comença amb una breu reflexió sobre els epistolaris, continua amb dos apartats genealògics i biogràfics dedicats als autors, i segueix amb una anàlisi de l'epistolari. El segon bloc consta d'un apartat dedicat a la bibliografia general utilitzada per redactar l'estudi, dos apartats dedicats a la producció bibliogràfica de cada autor $\mathrm{i}$, finalment, clou amb una transcripció anotada i comentada de les onze cartes de l'epistolari, que es conserven al Museu de Menorca.

Ghanime, Albert, «Els epistolaris i la història cultural». Cercles. Revista d'Història Cultural, 24, 237-239. ISSN: 1139-0158. ISSN-e: 1699-7468. DOI: 10.1344/cercles2021.24.1008. Data de recepció: 7/3/2021. Data d'acceptació: 3/5/2021. 
L'autor de l'estudi és Valenciano, però l'obra ha comptat amb l'estímul i la colllaboració de diferents especialistes, com ara Fina Salord i Antoni Guasch Bosch, entre d'altres, dins de la millor tradició de collaboració erudita del set-cents. El responsable de la traducció del llatí dels textos ha estat Xavier Patiño, cap de la secció de llengua i literatura de l'Institut Menorquí d'Estudis.

L'obra no té introducció, penso que imprescindible, però les dues pàgines dedicades a la reflexió sobre els epistolaris supleixen la mancança. Es tracta de dues pàgines interessants però massa breus. Amb referències a Ciceró, Erasme de Rotterdam, Dilthey, Lucien Febvre i Carme Figuerola, Valenciano valora les característiques dels epistolaris i justifica la seva importància com a font de primera mà per a la reconstrucció històrica.

Valenciano ha fet un important esforç de reconstrucció de la vida de dos individus representatius del món erudit insular de finals del XVIII i principis del XIX. El seu ha estat un treball detectivesc, erudit, un treball encomiable d'arxiu, conscient que la reconstrucció documental d'una trajectòria personal i familiar és fonamental per fer una bona interpretació biogràfica. Una altra característica del treball de Valenciano és que, a mesura que segueix, localitza i/o descarta línies d'investigació per confirmar o rebutjar una dada, ens explica el procés de recerca i apunta les fonts i els arxius on poder localitzar informació vital per entendre millor els orígens d'un personatge i el seu llinatge.

La trajectòria vital dels diferents membres dels dos llinatges ens dona molta informació sobre el segle XVIII mallorquí i menorquí. Ens fem una idea dels recursos de les famílies, dels impostos que pagaven, dels matrimonis per interessos familiars i econòmics, dels índexs de mortalitat de la població, del nombre de fills, etc. Hi ha un moment, però, en què el lector es perd entre tants cosins, germans, pares, mares i oncles. Aquí està el defecte, però també la virtut i la utilitat d'aquest tipus d'estudi detallat, meticulós. 
Cal dir-ho, Valenciano ha dut a terme un treball d'orfebreria genealògica i, com a conseqüència, ha posat al descobert dades d'arxiu que contradiuen afirmacions i dades que havien estat donades per bones fins ara. Francesc Pons i Carreras, alumne que fou de Joan Ramis i Ramis, va escriure un llibre biogràfic sobre el seu mestre. En aquest treball laudatori afirmava que la família de Joan Ramis era de Palma, però la documentació demostra que per part de pare la família era originària d'Inca. Aquest és simplement un detall, per a molts potser irrellevant o que no justifica un treball d'aquestes característiques, però la verificació d'una dada no és l'objectiu sinó una de les conseqüències d'una recerca ben feta, rigorosa, basada en fonts primàries i no en interpretacions basades en fonts secundàries no contrastades.

El veritable epicentre i la raó de ser de l'epistolari és el treball erudit de Joan Ramis i Ramis. Lluís de Vilafranca és un estret collaborador, que l'assessora i l'ajuda en la seva recerca sobre el passat de l'illa de Menorca. Els suggeriments i el suport moral són constants. Vilafranca li facilita molta informació sobre diversos temes i molt especialment sobre personatges rellevants de l'illa per a l'obra Varones ilustres de Menorca.

A l'epistolari, però, no s'hi troba cap referència a la situació política de l'època, ni a la local, ni a la nacional ni a la internacional. Des d'aquest punt de vista, l'epistolari és decebedor, però no li podem demanar a la documentació una informació que no ens pot donar. Les cartes tracten de llibres, de dades erudites, d'erudits i de temes d'estudi. En aquest sentit, són una aportació interessantíssima per a la reconstrucció de la cultura balear de finals del set-cents i principis del vuit-cents. els autors, citats a la referència que apareix a l'inici del document. 